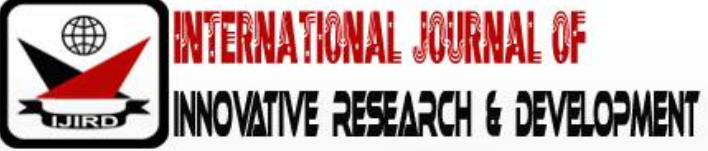

ISSN 2278 - 0211 (Online)

\section{Vocational Training Education and Targeted, Individual, Structured, Integrated Program for Students with Autism (TISIPFS)-A}

\author{
Maria Drossinou Korea \\ Assistant Professor, School of Humanities and Cultural Studies, \\ University of Peloponnese, Kalamata, Greece
}

\begin{abstract}
:
In the present study, we are addressing the problem of education and vocational training with regard to the narratives for future employment of students with autism according their four-year attendance in the Unified Special Vocational Gymnasiums and Lyceums (USVGL). In the methodology, we use the study of bibliographic texts and data from one case study with autism we highlight the narrative explores Greek legislation for students with disorders in the autism spectrum. According to the normative texts for future knowledge and work, they are taught general education courses, orientation courses in certain fields of study, and elective courses. In this context, the case of a twenty-eight-year-old man with autism at the Agricultural University and his low-paid employment adventure, the library and the reading room are being discussed. In our results, we have proved two key themes emerged regarding the narratives: 1) the enhance transdisciplinary processes to inform transition planning and teaching and educational vocational interventions; and 2) the facilitation comprehensive and developmentally appropriate employment transition services over a life course. In conclusion, businesses, employers and public authorities need to understand regulatory changes in education, vocational training and the autism culture. According to this, the discussion for future employment of autistics can accommodate their education expectations of USVGL. So, means that they can exercise their rights for equal education and vocational training and respond positive to the employers.
\end{abstract}

Keywords: Autism, vocational training, inclusion case

\section{Introduction}

\subsection{The Problem of Vocational Training Education}

Many people with autism (American Psychiatric Association, 2013) can experience social disadvantage and exclusion, as well as exclusion from the labor market. Adults with autism often lack the support they need to gain and maintain employment. As the researchers Hillier; Campbell; Mastriani; Izzo; Kool-Tucker; Cherry and Beversdorf have published in the magazine Career Development for Exceptional Individuals, (2007) referring to the two-Year Evaluation of a Vocational Support Program in the Adults on the Autism Spectrum.

The area of employment for the people with autism is another serious factor for the Inclusion and Community living and his research is limited and the issues are poorly understood the texts as this of the Commission on Equality and Human Rights in Great Britain (2010). This is drawing up a comprehensive technical guide with legal details on apprenticeship at work and vocational training for People with Disabilities and recognizes the social model of special education, signing the text on parity at work. According the team researchers of Hedley, and their research about the employment programs and interventions targeting adults with autism spectrum disorder, the adults with autism often lack the support they need to gain and maintain employment and can experience social disadvantage and exclusion, as well as exclusion from the labor market (Hedley et al., 2017). These empirical studies were limited by poor participant characterization, small sample size and/ or a lack of randomization and use of appropriate controls.

The researchers from Olga Tennison Autism Research Centre and Cooperative Research Centre for Living with Autism (Autism CRC) in Australia and from the University of Calcutta in India, (Hedley et al., 2017) were exercises articles and organized into the themes as the employment experiences, employment as a primary outcome, development of workplace skills, non-employment-related outcomes, assessment instruments, employer-focused and economic impact. They were systematically study Web of Science, Medline, PsychINFO, ERIC and Scopus databases searched through the 10 review and 50 empirical articles, comprising $\mathrm{N}=58,134$ individuals with autism. In this systematic review, empirical peerreviewed studies on employment programs, interventions and employment-related outcomes in individuals with autism spectrum disorder over 18 years with and without intellectual disability were identified and evaluated. From these outcomes to previous work in the area the future research must will be require a multidisciplinary and multifaceted 
approach to explore employment outcomes on the individual, the family system, co-workers and the employer, along with the impact of individual differences on. The primary and secondary hypotheses and objectives of the study.

The primary secondary hypotheses and objectives of the study was if the Targeted, Individual, Structured, Integrated Program with emphasis to vocational education could help Students with Autism (TISIPfS)- A because each person with autism is unique and needs a completely individualized approach at job searching and employment.

The secondary hypotheses research exercises if the special education in the schools as the Unified Special Vocational Gymnasiums and Lyceums (USVGL), in Greece could support the Students with Autism because the employment sustainability and work efficiency depend on training, working conditions and workplace adaptations.

At the end, it be study if the how do the hypotheses of Targeted, Individual, Structured, Integrated Program (TISIPfSA) with emphasis to vocational education research design relate to the programs of the Unified Special Vocational Gymnasiums and Lyceums (USVGL).

The theoretical and practical implications, according the International Classification of Functioning, Disability and Health Core Sets for autism spectrum disorder, in holistically have examine the employment in the present work and it has been founded the same with the Scott, Milbourn, Falkmer, Black, Bölte, Halladay, Lerner, Taylor, \& Girdler (2019). So, summarizing the relevant arguments and the past evidence, gives us the sense of why there need to light the Targeted, Individual, Structured, Integrated Program for Students with Autism (TISIPfS) - A and vocational training education and what was done.

\subsection{The Importance of the Problem to Students in the Upper Secondary Education with Autism}

The problem deserves new research because the students in the upper secondary education with autism do not have the opportunity to work for a long time under employer who knowing their difficulties (Scott, et al., 2019). So. the purpose of the research that summarizes the material preceding it according the literature reviews as well as theoretical and methodological articles, also clearly state the reasons special secondary vocational education for the persons with autism. The pedagogical instrument as the Targeted, Individual, Structured, Integrated Program for Students with Autism (TISIPfSA) used for the complex problem in the upper secondary education (Figure 1). As the that the reported content is important and how the Unified Special Vocational Gymnasiums and Lyceums (USVGL) could be support to employability of adults with autism. This article fits into the cumulative understanding of the field of special education and training in the higher education. The discussion around the relevant related literature concentrate to the researchers as Howlin (1997), who has described in the book for Autism and how preparing for the adulthood and with the research for an 8-year followup of a specialist supported employment service for high-ability adults with autism or Asperger's syndrome (Howlin et al., 2005).

\subsection{Describe Relevant Scholarship}

The present study does not have any Relevant Scholarship and has not received funding.

\subsection{State Hypotheses and Their Correspondence to Research Design}

Based on empirical research on the Diversity and Inclusion in Higher Education (Parham, 2014), we have found that adults with autism can work under certain conditions. These are summarized in upper secondary education and vocational training as well as in the way it is linked to the local labor market. In the cases, we have described the problem of defining the target, respecting and understanding the specificities and promoting integration programs of intervention directly linked to the social stations with which the adult person with autism coexists. In the present study, we are addressing the problem of education and vocational training with regard to the narratives for future employment of students with autism according their four-year attendance in the Unified Special Vocational Gymnasiums and Lyceums (USVGL). In the methodology, we use the study of bibliographic texts and data from one case study with autism we highlight through the narratives explores Greek legislation for students with disorders in the autism spectrum. According to the normative texts for future knowledge and work, they are taught general education courses, orientation courses in certain fields of study, and elective courses. Also, in the fourth grade of USVGL be taught theoretical and laboratory courses in continuation of technological and vocational courses. So, with this they are supported the apprenticeship and the practices in the laboratory lessons without the special professors knowing and using the Targeted, Individual, Structured, Integrated Program (TISIPfSA) with emphasis to vocational education.

\section{Method}

The research is empirical and bibliographic. It refers to data in the field of special education and training with emphasis to upper secondary level. In the methodology, we use the study of bibliographic texts and data from one case study with autism we highlight the Greek legislation for students with disorders in the autism spectrum ( Law $3699 / 2.10 .2008 / 199,2008$ ). According to the normative texts for future knowledge and work, they are taught general education courses, orientation courses in certain fields of study, and elective courses. Also, according to the observation methodology, the teaching priorities (Drossinou-Korea \& Bakogianni, 2018) and the intervention methodology of persons with autism the method has evolve and is implemented in five separate stages for the creation of an TISIPfSEN program with an emphasis on a case study of a twenty-eight-year-old man with autism at the Agricultural University. The transition of students with Special Educational Needs (SEN) from secondary to tertiary education is approached with the schools as the Unified Special Vocational Gymnasiums and Lyceums (USVGL). The cases of students with SEN in the Agricultural University of Athens has been published in detail in the research it is timeless and present the process of transition from the upper secondary education to the period from 2002 until 2018. The Targeted, Individual, Structured, Inclusion 
programs of pre-vocational readiness for students with Special Education Needs (TISIPfSENs) has describe the disease of teaching methodology and transition in special vocational schools (Drossinou Korea \& Periferakis, 2018). The transition for the SEN students who until 2000 are called in Greek language with the phrase "Physically Weak" is supported jointly by Student Care and the Interconnection Office. The survey involved 71 students, of whom 50 had certified with SEN (10: girls). In the methodology, we used material from weekly individual sessions, monthly micro-group meetings to discuss the mnemonic techniques and bimonthly open meetings on general counseling.

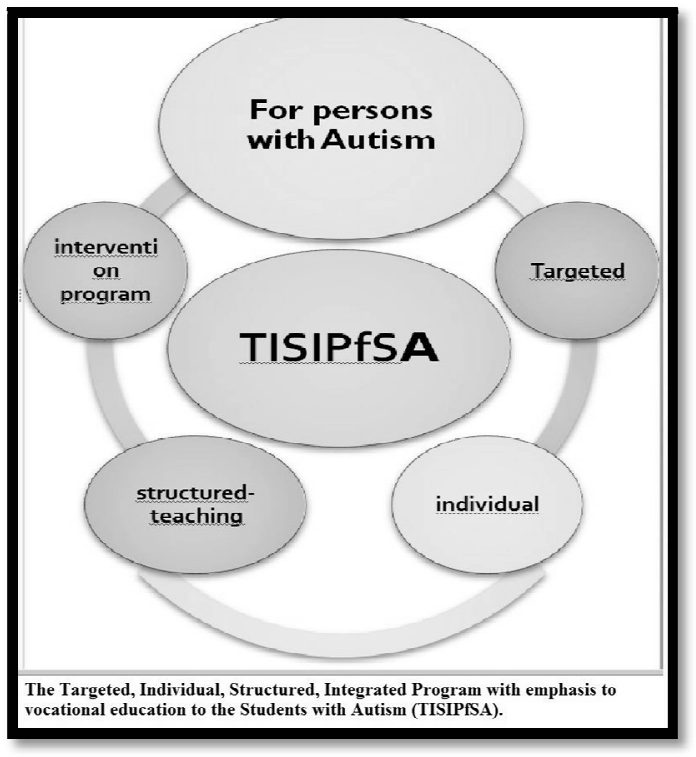

Figure 1: The Pedagogical Tool "Targeted Individual Structured and Integrated Program for Students with Autism" (Tisipfs) - A

Case study: Student history with autism. In this context, presented the case study as the impact of the SEN group on the specific learning difficulties and the language reality of people with autism without mental disability. Kostas, is confirmed in this case that it was diagnosed with dyslexia and had been supported for 12 years with speech therapy to end up studying at night secondary vocational and technical high school. He has been understanding reading the texts and faced the reading difficulties through naming speed tasks (Dahhan et al., 2016). He participated in Pan-Hellenic Examinations using the provisions for facilitating oral evaluation of candidates with special educational needs. As person with Asperger was diagnosed in the Fifth Year of the School by an adult test with Attention Deficit Hyperkinetic Disorder (ADHD) received electronically, printed, filled in, and posted by conventional mail. The test was conducted by the University Clinic at the Aigenetio Hospital, based on corresponding British Tests. The first part of the narrative here is completed and the questions that arise are enough as the below:

- What it is happened all these years with the diagnosis of dyslexia?

- Where was the mistake? In the mental health center's diagnostic team, in the speech therapists, in his parents, and his expectations of introducing their child to the University, in the education system because is unable to "scrape" autism and early signs from the very young ages?

Also, we note that Kostas has refused to receive medication although he knows that psychostimulant medications are the oldest prescriptions and that cognitive behavioral methods can complement this ADHD treatment (Happé, 2003). The comprehension problems were addressed by the fragmentation of the target in the semester courses attended and examined each time. The negotiation of the student with the university professors took place gradually and after constant urges to dare and talk about special learning difficulties (dyslexia) applying the Targeted, Individual, Structured, Integrated Program with emphasis to vocational education to the Students with Autism (TISIPfSA).

This was accompanied by the protocol of the individual counseling session in which the pupil's presence recorded the subjects of the discussion and related to the individual method of study, the timetable. This describes the completion of the academic obligations to obtain a degree and of course to refer to its difficulties without fear of rejection.

It was also discussed the meaning of the content of the report with the description "specific difficulties in learning evolutionary dyslexia", as it was formulated by the Medical and Pediatric Center and the Mental Health Center.

The autistic student, Kostas completed his studies and at the same time he was working on small jobs at the University Campus such as the guided tour of the University's school visitors and finally the library with the computer. The work in the library continued for a short time after graduation. His pay was poor and did not allow him to live with the dignified way. So, many times, he was be taking food from the social grocer and was be accepting second-hand apparel and footwear from the members of the university community.

The research tools are applied as a part of education edit and used as pedagogical tools in a case study and called as Targeted Individual Structured and Integrated Program for Students with Autism (TISIPfS)-A. This negotiates the heterogeneity of persons with Autism difficulties and attempts to achieve solutions in conventional classes, united, because it is impossible, for economic, social and pedagogical reasons, to address the problem of education by setting up different secondary schools' context. The TISIPfS-A unfolds in five phases (grapheme, 1) of a specific teaching methodology 
as a part of interventions with the systematic empirical observation and the data the intervention teacher collects through the participatory teaching process and refers to the individual, family, school history and the diagnosis of the individual. The first phase of TISIPfSA refers to systematic empirical participatory observation. It considers the student's individuality, family and school history based on parents 'and teachers' reports. Also, the observations of the special educational training and the data of the learning disabilities have recorded in the diagnosis from the public services. The Informal Pedagogical Assessment (IPA) is the second phase of TISIPfS-A. The observation method is used to gain information about the individual's cognitive level and to record his difficulties. The observed behavior is encoded using an observation key, the so-called Basic Skills Checklists (BSC). These include the topics with learning readiness activities in the topics from the oral speech, psychomotricity, mental abilities and emotional organosis according the objectives and the modules the Framework for the Curriculum for Special Education (FCSE). The lists help to identify the student's differences in the expected development of their abilities and put the teaching priorities and individual study.

The Schools as the Unified Special Vocational Gymnasiums and Lyceums (USVGL) are a recent transformation of special schools into secondary education (grapheme, 2). In the methodology is being studied as yet another factor that brings about changes in the lives of people with autism, especially in terms of their education and future employment. In particular, the curriculum of school USVGL examines whether it can promote individually targeted, structured, structured and diversified teaching vocational plans to support autistic people in their smooth transition to tertiary education. For this reason, the sample of students from the Agricultural University as well as the case study of the 28-year-old autistic student are used in the methodology as evidence for the knowing the SENs of the students and compared to the content and requirements of the academic programs.

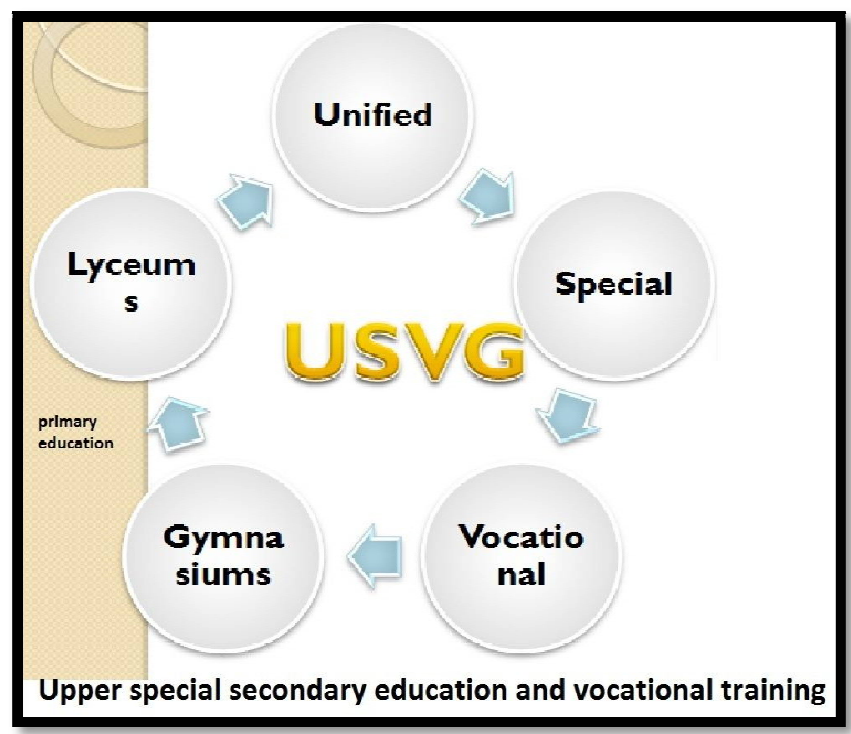

Figure 2: The Unified Special Vocational Gymnasiums and Lyceums (USVGL)

The limitations of observation were found in the fact that its records information from the individual narratives. These have referring to the experiences and feelings from the school's years in the primary and junior education through the memories. These contain all memory pictures from the periods of the interventions in the private centers for speech therapy, psychotherapy (CIPPA: Coordination Internationale de Psychothérapeutes, Psychanalystes et membres associés s'occupent de personnes Autistes, 2019) and special education and "negative" scenes which they have be lived.

\section{Results and Discussion}

The findings highlight the importance of knowing and understanding the characteristics of the autism spectrum disorder, and consequently, the employment needs emerging from it. In our results, we have proved that the narrative for future employment attempts to approach the educational law in depth and to explain how it can be applied in practice by improving the meaning of the work and employability of people with autism disabilities (Drossinou Korea, 2017). These findings from the case study can be useful in the process of special education and vocational training as well as in the workplace after employment with the aim to achieve sustainable employment (Hedley, et al., 2017). So, two key themes emerged regarding the narratives: 1 ) the enhance transdisciplinary processes to inform transition planning and teaching and educational vocational interventions; and 2) the facilitation comprehensive and developmentally appropriate employment transition services over a life course. According to this, the discussion for future employment of autistics can accommodate their education expectations of USVGL. So, means that they can exercise their rights for equal education and vocational training and respond as employers.

The enhance transdisciplinary processes to inform transition planning and teaching and educational vocational interventions is limited.

The findings highlight the limit of knowing and understanding the characteristics of the autism spectrum disorder in the University and consequently, the employment needs emerging from it. In our results, we have proved that the narratives for future employment attempt to approach the educational law in depth and to explain how it can be applied in 
practice by improving the meaning of the work and employability of people with autism disabilities (Wehman et al., 2016). Special education services in Greece are very poorly trained in the teaching of professional skills and we would not say enough about people with autism ( Law 3699/2.10.2008/199, 2008). Through the case study we recorded that our student had not been prepared for his transfer to the University. Despite the fact that the expectations of the family, and especially of the mother, sought professional rehabilitation by entering it. The special education was exclusively devoted to the development of academic skills oriented to writing, reading and mathematics. The consequences were recorded as findings from our eight-year study with the student of the Agricultural University, which we encountered every week except for the Christmas, Easter and summer holidays. The reinforcement of interdisciplinary procedures seems to stop, providing facilities such as the oral examinations in order to assess the adequacy of certain courses which they are leading to the University. The prospect of professional employment is not part of the planning of the transition from the Hight secondary education to tertiary. The below questions it is a part of the Targeted, Individual, Structured, Integrated Program with emphasis to vocational education to the Students with Autism (TISIPfS)- A, as:

- What will I do when I graduate from undergraduate studies? Or even

- Can I meet the requirements of the academic program at the University or what do I want to do to get my own bread (* i.e. Phrase in Greek language and means "to have my own money" or "to have my autonomy")? Or

- What can I do professionally and what I want too much to be happy?

These personal questions were absenting from the life plan of the person with autism. Event that was the subject of every weekly discussions and every time through the applying the (TISIPfS) - A.

The facilitation of comprehensive and developmentally appropriate employment transition services is not for all the life course.

According to this, the Unified Special Vocational Gymnasiums and Lyceums (USVGL) seem to be not giving to students with autism the professional training courses but also the apprenticeship programs with the help of special pedagogues. On the other hand, entrepreneurs ignore the employment opportunities of people with autism. The narratives come from the total number (table, 1) of students $\mathrm{N}=71$ with an average age of 28,5 year, who I have met in the seventeen years between 2002-2018. The students with the special education needs (SEN) $\mathrm{N}=60$ had an average age of 28,5 year, of these, $\mathrm{N}=10$ were girls with an average age of 26,7 years. The students with specific learning difficulties with emphasis on dyslexia, $\mathrm{N}=40$, all boys had an average age of 27,7 years and belong to the students who have were diagnosed as SEN. Only the students with the autistic spectrum disorders, $N=11$, all men had an average age of 29,3 year, and from them 4 students were reported with the diagnosis of the Asperger Syndrome. The student of the case study was one of them. All students who they have arrived in the university, had finished high school, but they differed in the types of upper high school. So, the 50 had finished General Lyceum, the 20 had finished upper vocational high schools and one who' s identified with the case study had graduated from the night vocational high school. All the participants in the study reported about the benefits of the expert support, both during the schools but not the same for the job searching and on the workplace. Employers as the University particularly emphasized the need of the ongoing support and cooperation from the professionals and mentors in the University and the transition to workplace.

\begin{tabular}{|c|c|c|c|}
\hline $\begin{array}{c}\text { Students And Secondary } \\
\text { Schools }\end{array}$ & $\begin{array}{c}\text { With The Special } \\
\text { Education Needs (SEN) }\end{array}$ & $\begin{array}{c}\text { With Specific Learning } \\
\text { Difficulties (Dyslexia) }\end{array}$ & $\begin{array}{c}\text { Disorders Of Autistic } \\
\text { Spectrum }\end{array}$ \\
\hline General Lyceum & 60 & 40 & 5 \\
\hline $\begin{array}{c}\text { Upper vocational high } \\
\text { schools }\end{array}$ & 10 & 20 & 1 \\
\hline $\begin{array}{c}\text { Night vocational high } \\
\text { school }\end{array}$ & 1 & 0 & 0 \\
\hline $\begin{array}{c}\text { Unified Special Vocational } \\
\text { Gymnasiums and Lyceums } \\
\text { (USVGL) }\end{array}$ & 0 & 0 & 11 average 29,3 years \\
\hline Total & 71 average 28,5 year & 60 average 27,7 years & \\
\hline
\end{tabular}

As it seemed, the facility for integrated and development-friendly transition services in employment has not be known to can implement the Targeted, Individual, Structured, Integrated Program with emphasis to vocational education to the Students with Autism (TISIPfS)-A. The consequences are important for the whole of life of students and the difficulties in the academic and career courses at the University. The zero in the (table1) for the Unique Specialized High Schools and Lyceums (USVGL) means that these are unaware of the existence of the pedagogical tool (TISIPfS)-A. Because the teachers have ignoring the support of experts both during of the teaching of lessons secondary into the school attendance and the linking with job search and the transition to the knowledge future workplaces (Drossinou Korea et al., 2019).

After this evaluation and interpretation of their implications, especially with regard to our original hypotheses we underline that the management of employees with autism requires structured and targeted training tailored to the special educational needs of people with autism. Moreover, it is underlined the need and willingness of school and university society of all member as the students, teachers, employers to obtain further knowledge for the autism and on how to manage these kinds of situations. The main learning outcome of the study focus in the close cooperation before, as well as during employment with the experts to autism which it is valued as essential. Awareness raising among employers and their knowledge of appropriate methods and techniques to work with employees with autism as well as providing relevant 
information on autism to management and colleagues is the key to sustainable employment. The role of the professionals in the education and the specialist has function so then thing as the bridge between the person with autism and frame employer and it is another crucial point.

In conclusion, businesses, employers and public authorities need to understand regulatory changes in education, vocational training and the autism culture (Lattimore et al., 2007). According to this, the discussion for future employment of autistics can accommodate their education expectations of USVGL. So, means that they can exercise better their rights for equal education and vocational training and respond as employers. Moreover, the point clues out of the Targeted, Individual, Structured, Integrated Program with the emphasis on vocational education to Students with Autism (TISIPfS) A has highlighted the importance of individual involvement in individual planning and empowering. Because also, it can be beneficial for the persons with autism and can lead to successful transition to the university academical program and can through the employment to join and be include the local community.

In conclusion, businesses, employers and public authorities need to understand regulatory changes in education, vocational training and the autism culture. According to this, the discussion for future employment of person with autism can accommodate their education expectations of USVGL (Drossinou, 2009). So, means that these persons can exercise better their rights for equal education and vocational training and respond as employers. The interpretation of the results took into account the sources of potential bias and other threats to internal validity, as the diagnosis. This concluding section brief the diagnosis of autism (Happé, 2003), which is based on the three fundamental deficits of socialization, communication and creative imagination. Two necessary diagnostic tools currently used by clinicians for the Diagnostic and Statistical Manual of Mental Disorders, 5th edition, (DSM-5) of the American Psychiatric Association (2013) and the International Classification of Diseases, 10th revision (ICD-10), World Health Organization (1990). So, according to DSM-5 (2013), a person with autism presents persistent deficits in the social communication and social interaction which vary depending on the situation. Also, the researches (Matson, et al., 2007) have referred to the social skills that they are defined as interpersonal responses that allow the adult person with autism from the childhood to adapt to the environment, through verbal and non-verbal communication.

The imprecision of measures with the informal pedagogical assessment was tested according to the second phase of the pedagogical tool (TISIPfS) - A, which identified the success of the interventions at the Agricultural University of Athens (Drossinou Korea, \& Bakogianni, 2018). This was measured by the completion of the academic studies of all people with autism, despite the difficulties we encountered each week on many levels associated with the individual diagnosis of each student. An important element in the success of these timeless interventions is the need to draw up an extended plan of interventions in the new University mapping services.

In the end of these discussion section the Vocational training education (Syriopoulou Delli et al., 2016) and Targeted, Individual, Structured, Integrated Program for Students with Autism (TISIPfS)-A (Drossinou Korea, \& Periferakis, 2018) has reasoned and justifiable comment on the importance of our findings. So, given the fact that the central objective of these diachronic interventions with the (TISIPfS) -A in the Agricultural University of Athens, have been highlighted the factual skills and elimination of the social exclusion of people with autism without mental disability. In order they integrate professionally and improve the quality of their lives. This research indicates the necessity of supporting autonomy, improving the quality of life and integrating into society, confirming the importance of professional skills in day-to-day interactions. The results met the targets set for each member of the group, allowing them to break social isolation and improve a little of their quality of life with employment on the local market (Parham, 2014). However, the (TISIPfS)-A could not help professionally who did not request for a specific support to discuss the choice of profession and did not seek to improve relationships with their colleagues through the small group work in the university as it have happening with the memory's techniques.

\section{Acknowledgements}

I would like to thank all the teachers of secondary vocational education that I had worked with them at the Pedagogical Institute for the valuable knowledge they have provided me. I would also like to thank the students I met at the Agricultural University and they are now employed as professional agronomists.

\section{References}

i. Law 3699/ 2.10.2008/ 199. (2008). Special Education and Training persons with Handicapped or / and persons with Special Educational Needs. Greek Official Governmental Gazette.

ii. American Psychiatric Association. (2013). Diagnostic and Statistical Manual of Mental Disorders Fifth Edition (DSM V). Washington, DC, London, England: American Psychiatric Publishing.

iii. CIPPA: Coordination Internationale de Psychothérapeutes, Psychanalystes et membres associés s'occupent de personnes Autistes. (2019). Retrieved 1 30, 2019, from 'Université Paris Diderot: www.cippautisme.org

iv. Dahhan, Noor Z. Al; Kirby, John R; Munoz, Douglas P. (2016, Nov). Understanding reading and reading difficulties through naming speed tasks. American Educational Research Association, pp. 1-37.

v. Drossinou- Korea, M., Kalamari, A. \& Bakoyanni, M. (2019, June). Educational Skills for Autistic People in Day Centers: Experiences and Observations of Volunteers - Philologists. Journal of Regional Socio-Economic Issues, 9 (Special Issue 1), pp. 55-65.

vi. Drossinou Korea, M. and Periferakis, Th. (2018). Targeted, Individual, Structured, Inclusion programs of prevocational readiness for students with Special Education Needs (TISIPfSENs). International Journal of Latest Research in Humanities and Social Science (IJLRHSS), 1(4), pp. 28-35. Retrieved 03 02, 2019, from http:/ / www.ijlrhss.com/ paper/ volume-1-issue-4/ 4.HSS-087.pdf 
vii. Drossinou, M. (2009). Teaching differentiations in labs of special vocational education and instruction (L.S.V.E.I.), with learning and pre-vocational readiness activities, in pupils with autism. Review of Educational Issues (15), pp. 121-134, in greek.

viii. Drossinou Korea, M. (2017). Special Education of person with Autism in France. Theory and Research in the Sciences of Education, 21, pp. 57-72. Retrieved 10 08 2019, from http:/ / periodiko.inpatra.gr/ issue/ issue21/ mobile/ index.html \#p=56,

ix. Drossinou Korea, M \& Bakogianni M. (2018, January). Methodology of Observation and Teaching Priorities in Students with Autism. Journal of Regional \& Socio-Economic Issues, 8(1), pp. 49-56.

x. Happé, F. (2003). Autism - Modern Psychological View. (i. g. D. P. Stassinos, Trans.) Athens: Gutenberg, in greek.

xi. Hedley, D; Uljarević, M; Cameron, L; Halder, S; Richdale, A., \& Dissanayake, C. (2017, Nov 18). Employment programmes and interventions targeting adults with autism spectrum disorder: A systematic review of the literature. Autism, 21(8), pp. 929-941, https:/ / doi.org/ 10.1177/ 1362361316661855.

xii. Hillier, A., Campbell, H., Mastriani, K., Izzo, M. V., Kool-Tucker, A. K., Cherry, L., \& Beversdorf, D. Q. (2007). TwoYear Evaluation of a Vocational Support Program for Adults on the Autism Spectrum. Career Development for Exceptional Individuals, (30), pp. 35-47.

xiii. Howlin, P. (1997). Autism: Preparing for adulthood. London and New York: Routledge.

xiv. Howlin, P., Alcock, J., \& Burkin, C. (2005). An 8-year follow-up of a specialist supported employment service for high-ability adults with autism or Asperger syndrome. Autism 9(5), pp. 533-549, https:/ / doi.org/ 10.1177/ 1362361305057871.

xv. Lattimore, L. P., Parsons, M. B., \& Reid, D. H. (2009). Rapid Training of a Community Job Skill to Nonvocal Adults with Autism: An Extension of Intensive Teaching. Behavior Analysis in Practice (2), pp. 34-42, https:// doi.org/ 10.1007/ BF03391735.

xvi. Matson, J. L.; Matson, M. L, \& Rivet, T. T. (2007). Social-Skills Treatments for Children with Autism Spectrum Disorders. An Overview. Behavior Modification, 31(5), pp. 682-707, https:/ / doi.org/ 10.1177/ 0145445507301650.

xvii. Parham, W. D. (2014). Second Special Issue on Diversity and Inclusion in Higher Education. Journal of Multicultural Counseling and Development, 42(3), pp. 130-131.

xviii. Schall, C. M., Wehman, P., Brooke, V., Graham, C., McDonough, J., Brooke, A., Ham W., Rounds R., Lau S., Allen, J. (2015, Dec). Employment Interventions for Individuals with ASD: The Relative Efficacy of Supported Employment with or without Prior Project SEARCH Training. J Autism Dev Disorders, 45(12), pp. 3990-4001, https:/ / doi.org/ 10.1007/ s10803-015-2426-5.

xix. Scott, M; Milbourn, B; Falkmer, M; Black, M; Bölte, S; Halladay, A; Lerner, M; Taylor, JL; \& Girdler, S. (2019, May). Factors impacting employment for people with autism spectrum disorder: A scoping review. Autism, 23(4), pp. 869-901, https:/ / doi.org/ 10.1177/ 1362361318787789.

xx. Syriopoulou-Delli, Chr.K; Papavassiliou, I. \& Karampilia, D. (2016). Review on Vocational Training and Employment of Individuals with Autism Spectrum Disorder. Journal of Educational and Developmental Psychology, 6(2) 84-96, https:/ / doi.org/ 10.5539/ jedp.v6n2p84.

xxi. Wehman, P. (2014). Autism, Transition and Employment: An Annotated Bibliography 2008-2014. Virginia Commonwealth University Richmond, VA: VCU Autism Center for Excellence VCU-RRTC.

xxii. Wehman, P; Brooke, V; Brooke, AM; Ham, W; Schall, C; McDonough, J; Lau, S; Seward, H. \& Avellone, L. (2016, JunJul). Employment for adults with autism spectrum disorders: A retrospective review of a customized employment approach. Journal Research in Developmental Disabilities, 53-54, pp. 61-72, https://doi.org/ 10.1016/ j.ridd.2016.01.015. 